\title{
Políticas de Representación: construcción y marketing de nuevas identidades en el espacio político-mediático
}

\section{Politics of Representation: construction and marketing of the new identities in the political mediaspace}

\author{
Liliana SUÁREZ NAVAZ \\ Departamento de Antropología Social y Pensamiento Filosófico Español \\ Universidad Autónoma de Madrid \\ liliana.suarez@uam.es
}

Recibido: 3 de mayo de 2011

Aceptado: 30 de mayo de 2011

\begin{abstract}
Resumen
Este trabajo presenta algunos hallazgos preliminares de la investigación sobre "Politicas de representación en el campo migratorio transnacional: producción, distribución y consumo de contenidos mediáticos en el contexto migratorio" (CSO2008-03022). A partir de la consideración teórica de algunos retos centrales planteados a la antropología en el contexto de globalización, describimos y analizamos la aparición reciente pero masiva de medios de comunicación orientados hacia la población inmigrante en España. Se profundiza en el análisis del contenido ofertado por estos medios, a partir de un estudio cuantitativo y cualitativo de los mismos, trazando una comparación con el espacio mediático generalista. Se analiza la construcción de la noticia en sus vertientes migratorias, transnacionales y de manera específica en su dimensión cultural, explorando la aparición de la nueva categoría etnocultural de "latin@s" en nuestro entorno. Finalmente, se ofrecen tres tipos ideales, referentes al tipo de vínculo que los nuevos periodistas de origen latinoamericano establecen con su "audiencia" y/o base social: instrumental, clientelar y orgánico. Concluimos con una serie de consideraciones sobre la importancia del estudio etnográfico del espacio público a través de una perspectiva transnacional, que aborde los procesos de comunicación política en los espacios político-mediáticos que nos configuran como ciudadanos.
\end{abstract}

Palabra Clave: migraciones internacionales, espacio público, antropología política de los medios y del periodismo, etnicidad, etnogénesis.

\begin{abstract}
This article explores some premilinary findings of the research on "Politics of Representation in the Transnational Migratory Field: Production, Distribution and Consumption of Media in Migratory Context" (CSO2008-03022). From an initial theoretical reflection on the main challenges Anthropology finds in the globalization context, we describe and analyze the recent burst of mass media oriented towards immigrant population in Spain. I delve into the analysis of content of these media, based on a quantitative and qualitative research,
\end{abstract}


comparing briefly the results with dominant media. I analyze the construction of the "news" in migratory, transnational and cultural dimensions, exploring the emergence of a new ethnocultural category new in Spain, that of "Latin@s". I finally offer three Ideal Types of the articulation of Latin American journalist with their audiences and their sociological grass roots organizations and communities: instrumental, clientelist, and organic. I then conclude through a series of considerations about the importance of the ethnographic work on the public space through a transnational perspective that deals with political communication processes in the new mediaspaces which shape our social world as citizens.

Keywords: International migration, public space, political anthropology of media and journalism, ethnicity, etnogenesis.

Referencia normalizada: Suárez Navaz, L. (2011). Políticas de representación: construcción y marketing de nuevas identidades en el espacio político-mediático. Revista de Antropología Social, 20, 229-261.

SUMARIO: 1. Inmigración y periodismo en España: los nuevos espacios político-mediáticos como objeto de investigación etnográfica. 2. Reflexiones en torno a la construcción del objeto de estudio: identidad, mercantilización y mediación comunicativa en procesos identitarios. 3. La explosión de medios especializados para inmigrantes en España: negocio y lucha contra la exclusión. 4. La construcción de las audiencias "latinas": contenido y recepción. 5. Periodistas latinoamericanos y los retos de la democratización del espacio mediático en España. 6. A modo de conclusión. 7. Referencias bibliográficas.

\section{Inmigración y periodismo en España: los nuevos espacios político-mediá- ticos como objeto de investigación etnográfica}

A partir de mediados de los pasados años ochenta, España experimenta una profunda transformación en su posición en el mercado laboral internacional. De ser un país que exportaba mano de obra no cualificada a Europa, pasa a convertirse en destino de los nuevos flujos migratorios que provenían inicialmente de África, y gradualmente, cada vez con más fuerza, desde América Latina o Asia. La sociedad española, aletargada por la autarquía dominante en la dictadura franquista, pasaba de una política de homogeneización cultural, impuesta desde el nacionalismo español, a una nueva etapa en la que las diferencias culturales peninsulares articulaban el sistema político. Esta multiculturalidad "interna" se transforma tras las nuevas dinámicas inmigratorias en una "diferencia profunda", siguiendo la propuesta del filósofo canadiense Kymklicka, que ha sido construida como externa, amenazante, problemática. Si la llegada de la democracia a España significó la creación de medios de comunicación protegidos por el derecho constitucional de la libertad de expresión, ¿no es cierto que profundizar en la democratización del espacio político-mediático debería incorporar esta dimensión cultural profunda en el espacio público? ¿Es por tanto un indicio del cumplimiento de derechos democráticos el que la inmigración y los inmigrantes ocupen un lugar protagonista en los medios de comunicación? Apuntamos al derecho intrínseco a poder comunicarse y, según Hubsband (1996) sugiere, a poder "ser entendido", como horizonte político-mediático, y nos proponemos explorar cómo se está desarrollando esté fenómeno hoy en España. En este 
trabajo presentamos de manera breve algunas de las premisas teóricas y hallazgos empíricos de la investigación realizada desde la Universidad Autónoma de Madrid en el proyecto I+D: Políticas de representación en campos migratorios transnacionales. Producción, difusión y consumo de contenidos mediáticos en el contexto migratorio (CSO2008-03022).

Desde principios de los pasados años noventa venimos siguiendo en nuestro Grupo de Investigación el fenómeno migratorio en España, observando patrones de asentamiento, analizando cadenas migratorias y dando seguimiento a procesos sociopolíticos generados en nuestro territorio ${ }^{1}$. Hemos descrito etnográficamente la transformación del modelo de ciudadanía en España como consecuencia de su incorporación al espacio económico europeo en 1986, con la creación de fronteras internas en una nueva sociedad donde la etnoestratificación y las divisiones legales se superpusieron a, y en algunos sectores reemplazaron, la tradicional división de clases que sostenía el régimen franquista (Suárez Navaz, 1999, 2004, 2007). A lo largo de los últimos años noventa, se establecieron las bases de una progresiva segmentación residencial y laboral que se entrelazaba con un nuevo paisaje multicultural en las ciudades y pueblos del territorio. Estos procesos eran parte de los más generales mecanismos de inclusión y exclusión de las sociedades occidentales contemporáneas, a los que España ha ido equiparándose en las tres últimas décadas. Más allá del estudio específico sobre los colectivos inmigrantes, nos interesa situar sus prácticas en el contexto de transformación del modelo de ciudadanía, considerada no como un concepto legal acotado y claro, sino como un sistema simbólico de representación de la pertenencia a la comunidad política. El estudio de estos procesos nos llevó a incorporar en nuestro marco analítico la perspectiva transnacional, pues observábamos etnográficamente que los límites marcados por la pertenencia a la nación no contenían ni mucho menos el imaginario de referencia de los migrantes asentados en nuestro territorio (Suárez Navaz, 1995b, 2008). Las familias transnacionales que se estaban conformando mediante las estrategias migratorias eran la argamasa de redes sociales que unían origen y destino, que incorporaban en las prácticas cotidianas de los inmigrantes los referentes transnacionales de su realidad y sus anhelos. Por otra parte, también fenómenos supranacionales, como la Unión Europea, creaban nuevos espacios de referencia identitaria en las poblaciones diversas del territorio español. Un nuevo etnoespacio globalizado configuraba los procesos de transformación de la ciudadanía, tanto en el eje de pertenencia como en el de la titularidad de derechos.

De este modo, en el seguimiento de las prácticas políticas de los migrantes que se habían asentado en nuestro país durante la pasada década de los noventa, descubrimos un nuevo actor invisibilizado bajo la poderosa representación del inmigrante como mano de obra, víctima o amenaza. En las asambleas de los colectivos con los que trabajábamos desde el año 2001 — senegaleses, ecuatorianos y rumanos—, nos

${ }^{1}$ El Grupo de Investigación mencionado se genera a partir del trabajo impulsado por Carlos Giménez en el Programa Migración y Multiculturalidad desde 1989, y desde entonces su aportación a los estudios migratorios ha sido destacada. Hace unos años fundamos el Instituto de Migración, Etnicidad, y Desarrollo Social de la UAM (IMEDES), en donde se inscribe este estudio. 
sorprendió que poco a poco acudían periodistas a cubrir los eventos. Mayoritariamente estos periodistas eran miembros del propio colectivo de inmigrantes, habían llegado al calor de las profundas crisis en sus países de origen y de la demanda laboral generada en España. Una vez en España, la mayoría había sufrido la larga travesía común a todos los inmigrantes de aquella época en nuestro país: trabajos precarios y mal pagados, ya fuera en la construcción, la agricultura o los servicios, y situaciones de precariedad legal e irregularidad administrativa. Las primeras etapas del asentamiento igualaban a gran parte de los inmigrantes que llegaban por aquel entonces, no importa el tipo de formación, habilidades de liderazgo y, en general, capital cultural y social que tuvieran en origen.

Estos nuevos actores inmigratorios cualificados iban a transformar el panorama de la inmigración en nuestro país. Poco a poco, algunos de los periodistas comienzan sus propias iniciativas mediáticas: pequeñas emisoras de radio, periódicos, páginas web. Entroncadas inicialmente en el tejido social generado a partir de la inmigración, estas iniciativas comenzaron a crecer exponencialmente, especialmente aquellas que provenían del colectivo latinoamericano. Estos medios juegan un enorme papel en la modulación del fenómeno migratorio: no sólo generan una diferente representación de este fenómeno social, sino que también tienen un profundo impacto en la construcción del migrante como una audiencia protagonista, un público consumidor, ciudadanos con opiniones divergentes a las expresadas en los medios de comunicación generalistas. Es este doble papel de los medios, forjados por unas realidades y necesidades propias de los migrantes, pero a la vez diseñados para influirlas, lo que los hace especialmente interesantes para los estudios socioantropológicos de las migraciones internacionales.

Siendo ésta su relevancia, destaca en el panorama académico de estudios migratorios en España la ausencia de un proyecto coherente e interdisciplinar, que se marque como objetivo el estudio de la producción, difusión y consumo de estos medios de comunicación. Por otra parte, existe en Europa y Estados Unidos un cuerpo de literatura académica que ha descrito la situación en base a estudios de caso y proyectos comparativos, pero destaca la debilidad sociológica de algunos de estos trabajos sobre las nuevas plataformas empresariales mediáticas. Y, aunque desde la Antropología ha existido un ya tradicional interés por los estudios de cultura popular y producción mediática y por el modo en que las "consumen" diversos sectores poblacionales, apenas se ha volcado esta preocupación en las investigaciones migratorias. Es nuestro interés, pues, aunar estos objetivos teóricos en un primer estudio interdisciplinar integrado, en el que valoremos de manera articulada: la economía política del surgimiento de estas plataformas mediáticas; la participación de los propios inmigrantes en los nuevos medios y de los nuevos profesionales en la red asociativa de los inmigrantes; los procesos de distribución en los nodos residenciales de estos colectivos; el contenido y la dimensión simbólica de estas construcciones mediáticas; y el tipo de influencia o el modo de recepción de los mismos por los propios inmigrantes residentes en nuestro país. 


\section{Reflexiones en torno a la construcción del objeto de estudio: identidad, mercantilización y mediación comunicativa en procesos identitarios}

El objeto de estudio no se limita al objeto de observación. La antropología construye teóricamente sus objetos de estudio y es desde este trabajo conceptual que la etnografía cobra sentido, como defienden Trouillot en su antropología del Estado y otros etnógrafos (Collier, Maurer y Suárez Navaz 1995). Frente a ciertas variantes empiricistas, la antropología contemporánea cuestiona la evidencia empírica de los fenómenos sociales tal y como éstos se aparecen ante nuestros ojos. El trabajo etnográfico aporta una trama metodológica integral de los fenómenos sociales que nos exige ir más allá de lo "empíricamente evidente". Éste es un desafío fundacional y común a otras ciencias sociales, pero los contextos contemporáneos de globalización y mediación cultural lo han agudizado.

En los estudios migratorios desarrollados en nuestro entorno, las ciencias sociales no han incorporado suficientemente las precauciones epistemológicas necesarias, generándose una variedad de estudios empíricos de carácter empiricista. El tratamiento de los fenómenos migratorios bajo las categorías fungidas por los aparatos institucionales, en calidad de "inmigrantes", o "integración", son un ejemplo de cómo lo "empíricamente evidente" impide aportar elementos de análisis riguroso de los procesos sociales. El trabajo antropológico, enfocado en las prácticas y procesos que asumen, construyen, o cuestionan estas categorías en lugares etnográficos diversos, permite entender más claramente, por ejemplo, cómo la identidad cultural es un efecto de las relaciones sociales concretas en que se generan. El caso de la "integración" de los "inmigrantes" debiera comprenderse antropológicamente, por tanto, a través de un trabajo analítico más ambicioso, que sitúe estos procesos en una transformación socioeconómica, de la cultura legal y política y del imaginario identitario producido tras la incorporación a la Unión Europea y a las "sociedades desarrolladas y modernas". Dicho en otras palabras, se trata de aprovechar el "objeto de observación", los "inmigrantes", para explorar procesos sociales de transformación cultural en nuestro espacio etnográfico cuyos efectos crean la aparente "evidencia" de su realidad como grupo social.

Los procesos migratorios son un espacio etnográfico privilegiado para explorar la construcción de las fronteras de la ciudadanía y los espacios de participación/ exclusión política e identitaria, el objeto de estudio específico de mi investigación. La cautela en relación a las categorías administrativas como unidades de análisis se refuerza con una perspectiva transnacional, que incorpora espacios de acción política y comunicativa más allá de las fronteras del Estado-nación. De nuevo, éste es un requisito no meramente empiricista: no se agota ni requiere simplemente el análisis de redes o circuitos migratorios transnacionales. Lo transnacional es más que un hecho empíricamente verificable - $\mathrm{O}$ no- una perspectiva que incorpora teórica y metodológicamente el reto de comprensión del efecto de la globalización en los procesos sociales locales que estudia la antropología.

Vertebran el objeto de estudio que abordamos tanto la perspectiva transnacional como el cuestionamiento de la categoría de "inmigrantes", y el análisis de los procesos políticos e identitarios que configuran nuestro espacio público. Los nuevos 
medios de comunicación, especializados en la población inmigrante, evidencian de entrada varios puntos de inflexión con la literatura antropológica que ha explorado el fenómeno migratorio en nuestro país. En primer lugar, destaca la heterogeneidad de clase en los colectivos de extranjeros asentados en el país. Este aspecto, aún insuficientemente estudiado, es clave para contrarrestar la representación de la inmigración como mano de obra no cualificada o cualificada, creando así una imagen polarizada de los procesos migratorios (Ley, 2011). El estudio de la migración introduce nuevos aspectos de análisis desde la perspectiva transnacional de la clase media:

Mientras sea imposible responder con una teoría coherente sobre por qué la clase media está migrando internacionalmente, es plausible ver esta migración internacional como una estrategia particular de movilidad, consciente o no, que lleva a su apropiación del capital social, económico y cultural... De forma más general, la movilidad internacional (de la cual es parte la migración internacional) se está convirtiendo en un componente central de la reproducción de la identidad de la clase media; las experiencias de movilidad ayudan a estratificar una clase media posindustrial creciente, donde las fronteras entre economía/cultura y entre consumo/producción son cada vez más difusas, y donde los mecanismo tradicionales de distinción [en términos bourdieanos] (educación secundaria o terciaria), están perdiendo su poder (Scott, 2006: 1107-09).

El estudio de los medios de comunicación especializados en la población inmigrante en nuestro país, así como la literatura que explora fenómenos similares en el entorno internacional (Carøe Christiansen, 2004; Georgiou 2006; Gillespie, 1995; Hargreaves y Mahdjoub, 1997; Karim, 1998; Rigoni, 2003; Viswanath, 2000; entre otros), demuestran que los periodistas de minorías étnicas o de colectivos inmigrantes se perciben por su audiencia como actores fundamentales en la transformación de una esfera pública hegemónica sesgada y a menudo racista. Mostraremos en éste trabajo el modo en que esto sucede en los medios que estamos abordando y específicamente para los periodistas de origen latinoamericano. Demasiadas veces, sin embargo, hay premisas tácitas en el estudio de estos fenómenos que permean el análisis. En concreto, nos interesa cuestionar la idea de que la identidad étnica y la situación socioeconómica o legal, que comparten los extranjeros en el país receptor, predisponen en los periodistas de origen minoritario un tipo de actitud "natural" para producir representaciones alternativas de la inmigración y los inmigrantes. Esto es, como mostraremos, falso, puesto que las variables étnicas o socioeconómicas no configuran en si mismas un colectivos homogéneo de inmigrantes, ni son una base "natural" para la acción. Y es también peligroso, ya que el análisis de los intereses económicos, que permean el espacio mediático, puede llevar a desestimar una exploración rigurosa de transformaciones sutiles que son cruciales para la democratización del espacio político-mediático, y que Husband, entre otros investigadores, nos insta a explorar y promover (1996).

Proponemos un análisis del conjunto de capitales económicos, sociales y simbólicos específicos del subcampo mediático, orientado hacia los inmigrantes en España 
a través de la teoría de campo social de Bourdieu, aplicada a la articulación entre la esfera mediática y los procesos migratorios. Estamos interesados en comprender las complejas relaciones socioeconómicas y simbólicas que configuran la posición de los periodistas y sus audiencias de origen extranjero en estos medios, las fuerzas que condicionan sus prácticas y acciones orientadas hacia la transformación del espacio público español, no sólo incluyendo los intereses y necesidades informativas o en general de consumo de los inmigrantes, sino además en reformular sus relaciones como profesionales vis à vis sus audiencias.

Revisemos primero brevemente algunas características centrales de la teoría de campos de Bourdieu y cómo la articula con lo que denomina campo periodístico. El campo social es una metáfora analítica y heurística que se refiere a:

un campo de fuerzas en el que los actores ocupan posiciones que estadísticamente determinan las posiciones que ocupan en relación al campo, siendo esta toma de posiciones orientada a bien conservar o transformar la estructura de relaciones de fuerzas constitutiva del campo. En otra palabras, el campo (por ejemplo el campo literario como un microcosmos que aúna los agentes e instituciones involucrados en la producción de obras literarias) es comparable a un campo físico de fuerzas; pero no es reducible a un campo físico - es el espacio de acciones y reacciones desarrolladas por los agentes sociales dotados de disposiciones permanentes, en parte adquiridas en esta campo social... Y mientras que están determinados por estas fuerzas en relación a sus disposiciones permanentes, son capaces de actuar sobre los campo, de maneras que están parcialmente construidas, pero con un margen de libertad (Bourdieu, 2005: 30).

Propone una teoría de campos interrelacionados, situados en relaciones de poder específicas entre ellos, donde los intereses económicos dominantes permean y configuran los campos sociales, pero no los determinan completamente. Bourdieu estaba interesado en facilitar instrumentos teóricos capaces de explicar el cambio social tanto como la reproducción: el concepto de habitus, que he explorado a fondo en otro lugar, aúna el predominio de las fuerzas estructurales y la posibilidad de agencia y cambio (Suárez Navaz, 1995).

De forma característica, la teoría de campos ha prestado especial atención a las dinámicas particulares, que constriñen campos sociales orientados hacia la producción de conocimiento, en especial, la política, las ciencias sociales, y el periodismo, porque "todos ellos reclaman e imponen una visión legítima del mundo social... son una área de luchas internas para la imposición del principio dominante de visión y división" (Bourdieu, 2005: 36). La dimensión simbólica no es reducible a las fuerzas económicas que condicionan la acción a través de los campos. Tampoco sucede así en los campos orientados hacia la producción del conocimiento. Éstos últimos son en particular los lugares de producción de las categorías a través de las cuales vemos el mundo y condicionan la acción. Son cruciales en la representación del mundo social, construyendo "el universo de presuposiciones tácitas que aceptamos como nativos de una determinada sociedad" (Bourdieu, 2005: 37).

Bourdieu considera al campo periodístico un crucial "objeto científico y civil" de análisis, porque "por una serie de razones, el campo periodístico ha ejercido cada vez 
más una influencia/sujeción ("hold")... en otros campos y en particular, en lo que refiere a la producción simbólica, en el campo de las ciencias sociales y de la política", y además "porque el campo social está perdiendo más y más su autonomía ... el crecimiento del peso de la economía dentro del campo está creciendo constantemente" (Bourdieu, 2005: 41-42). Este proceso está vinculado al incremento cada vez más acentuado de los intereses comerciales en los medios, produciendo una dependencia estructural de las "tasas de audiencia" y de la investigación sobre los potenciales intereses de las audiencias. Los peligros asociados a este control de medios comerciales en el resto de los campos especializados en lo social y lo cultural es una perspectiva crucial del trabajo de Bourdieu. ¿Hasta qué punto, se pregunta el sociólogo, estos medios están produciendo "uniformidad, censura, e incluso conservadurismo"? (Bourdieu, 2005: 44) ¿Cuáles son los recursos para la contestación y la producción de conocimiento crítico capaz de cuestionar algunas de las presuposiciones tácitas en nuestra percepción del mundo social?

Adoptamos esta perspectiva en nuestra exploración del campo periodístico orientado hacia las poblaciones migrantes, situando el análisis dentro del más amplio contexto de campos sociales que configuran las formaciones sociales contemporáneas. La explosión de medios orientados hacia los inmigrantes está íntimamente relacionada con los intereses comerciales y económicos, impulsados por las "investigaciones de audiencia" promovidas por el sector empresarial. En concreto, en nuestro trabajo debemos añadir a esta perspectiva la consideración cuidadosa de las dinámicas particulares de los procesos migratorios en España. La articulación del campo periodístico con lo que, en mis trabajos anteriores (Suárez Navaz, 2008, 2010), he denominado campo migratorio transnacional nos dirigirá hacia un análisis más congruente de la posición de los nuevos periodistas latinoamericanos, de sus estrategias de movilidad social, y de su papel específico en la transformación o reproducción de fuerzas dominantes e imaginarios que excluyen, reducen, o demonizan la inmigración en España.

Los medios generalistas en nuestro país comparten y promueven una serie de categorías que dominan el imaginario simbólico de la migración: "nativos" vs. "extranjeros"; "legales" vs. "ilegales"; "ricos" vs. "pobres"; "desarrollados" vs. "sudesarrollados"; "europeos" vs. "no Comunitarios"; e incluso "blancos" vs. "personas de color"; entre otras (Dick 2006, 2007; Santamaría 2002; Suárez Navaz, 1999, 2005; Suárez Navaz et al., 2007a, 2007b;). Como hemos dicho, hay suficientes investigaciones que demuestran desde distintos enfoques disciplinarios este argumento aplicado a los medios generalistas españoles (Bañón, 2002). En respuesta a ello, ha surgido en la sociedad civil y a través de las instituciones públicas proyectos sistemáticos de análisis de estos sesgos producidos en el campo mediático, como el trabajo activista y científico de Mugak, entre otros ${ }^{2}$. Los periodistas latinoamericanos entrevistados,

${ }^{2}$ Participante en el proyecto de investigación de la Universidad Autónoma de Madrid, Mugak - Centro de Estudios y Documentación sobre Inmigración, Racismo y Xenofobia, impulsado desde SOS Arrazakeria - viene desarrollando su labor desde 1995. Edita desde 1997 la revista Mugak, de periodicidad trimestral, y mantiene, junto con Xenomedia de Barcelona, el Observatorio de la Diversidad. En él se hace un seguimiento diario del papel que juegan los medios y, en particular, la prensa, 
al igual que los inmigrantes en general, se refieren y denuncian, de manera unánime, a este tipo de política de representación dominante, como sesgada, etnocéntrica, discriminadora y racista. Sus prácticas sociales, políticas y culturales han incorporado el espacio mediático como un espacio privilegiado de lucha, y se han involucrado en una construcción activa de representaciones alternativas de la migración y los inmigrantes. Enfatizan la dimensión social y política de la esfera mediática como determinante en la acción y participación en el espacio público, y estiman que los medios surgidos recientemente para los inmigrantes son importantes. Estiman no sólo la construcción de representaciones alternativas, sino, de manera rotunda, la necesidad de que éstas sean responsables y rindan cuentas ante sus intereses y necesidades, como veremos, altamente heterogéneos.

\section{La explosión de medios especializados para inmigrantes en España: nego- cio y lucha contra la exclusión}

Desarrollamos la base de datos sobre medios de comunicación orientados hacia y/o producidos por inmigrantes (MECODI) a partir de 2003, cuando el único registro existente apenas recogía una veintena y, sin embargo, su creciente importancia era evidente etnográficamente (Gaya, 2003). De 2007 a 2009 registramos en MECODI más de 300 proyectos mediáticos, absolutamente diversos en lo relativo a públicos, objetivos, formato, periodicidad o soporte. Respecto a la producción y al consumo de estos medios, destacamos la relevancia del contexto urbano. Madrid y Barcelona se consolidan como centros de producción principales, y es que no sólo en las grandes urbes hay más infraestructuras que posibilitan los proyectos, sino que además es en estas ciudades donde se asienta la mayoría de quienes componen su público.

Este registro también hizo patente cuáles eran los colectivos que mayor número de medios tenían a su disposición, y en qué soporte: prensa escrita, radio, televisión o web. Descubrimos que la creación de medios no responde ni a las dificultades de comprensión lingüística, ni al número de personas establecidas en España. Por ejemplo, a pesar de que los colectivos de marroquíes o rumanos son los más numerosos y tienen más dificultades de acceso a, y comprensión de, los medios generalistas, cuentan con muy pocos medios creados aquí por ellos y para ellos. En contraste, eran los medios en español, orientados hacia los colectivos latinoamericanos, los que estaban creciendo exponencialmente en nuestra base de datos, además de ser pioneros y mayoritarios en la elaboración de prensa escrita y en radio. El uso de la televisión digital, a menudo de los países de origen o cadenas transnacionales, es más relevante para colectivos como el marroquí o el rumano, restando así posibilidades de creación mediática específica en el espacio específicamente migratorio. La crisis económica y el impacto de las nuevas tecnologías en la prensa escrita han producido numerosas transformaciones en este espacio mediático orientado hacia

y se edita una Revista de Prensa, que se envía diaria y gratuitamente a quienes lo solicitan con los contenidos que aparecen en el día a día en más de veinte periódicos del Estado español (ver http:// www.mugak.eu). 
los inmigrantes, con una tendencia sostenida hacia la digitalización de numerosos proyectos mediáticos.

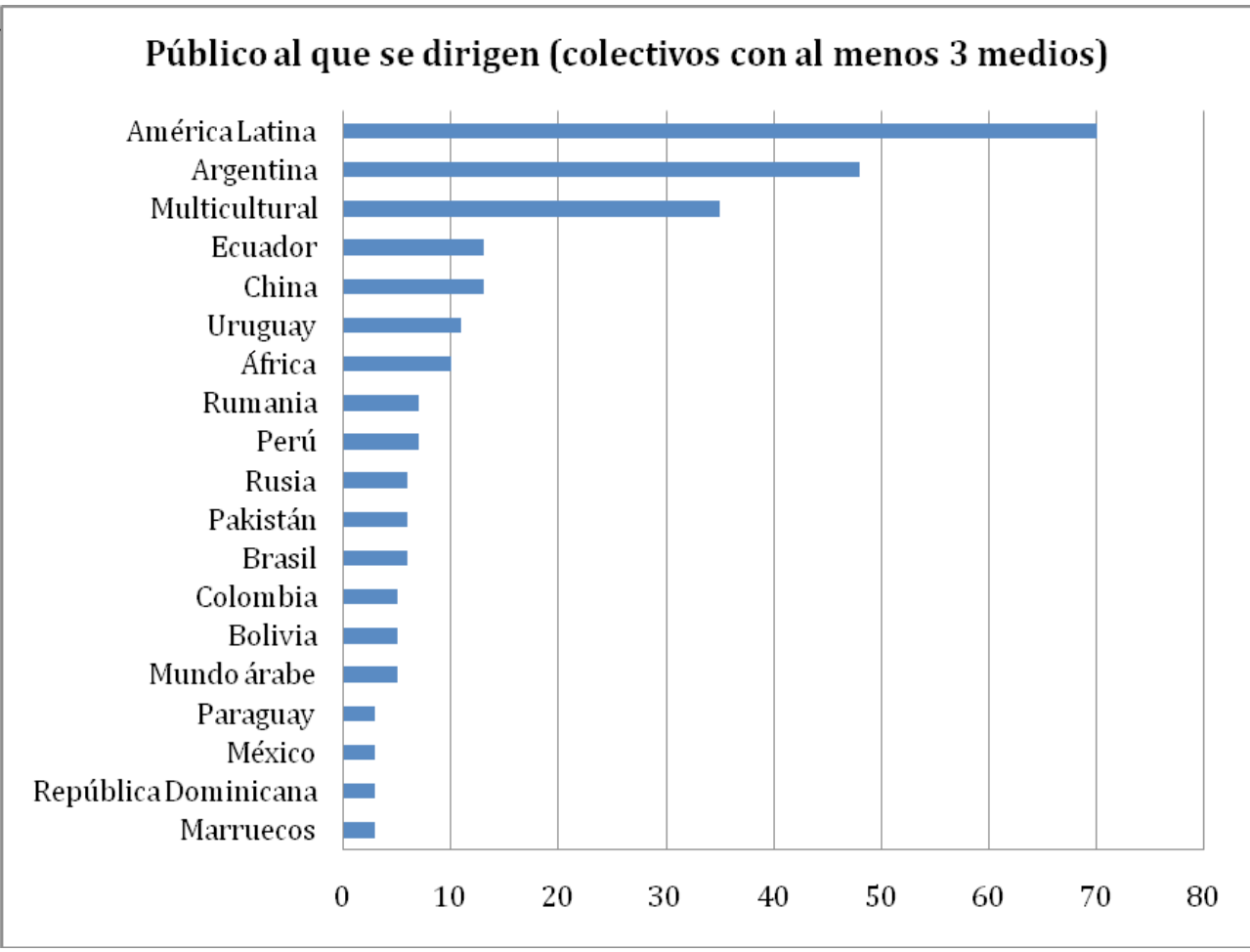

Gráfico 1.Público al que se dirigen. Fuente: Alicia Ferrández, para Suárez Navaz y Ferrández, 2010

Nuestro interés por este fenómeno partía de su consideración como actores políticos relevantes en el campo migratorio transnacional. Los periodistas, mayoritariamente originarios de los mismos países de emigración, asistían a las asambleas de las asociaciones, cubrían los eventos comunitarios — como los torneos de fútbol, el Inti Raymi, el Paukar Raymi, el Pase del Niño, la fiesta de la Virgen del Cisne o de la Virgen del Quinche, celebraciones rituales de los ecuatorianos con los que yo trabajaba (Suárez Navaz, 2008, 2010) - , las fiestas "nacionales" celebradas por los emigrantes, o las visitas de políticos o cantantes del país de origen. Las asociaciones, conscientes de la importancia de la dimensión mediática de estas revistas tanto en España como en Ecuador - en mi caso-, les invitaban a los eventos e intentaban mantener una relación estrecha con varios periodistas. En un grupo de discusión, realizado con dirigentes destacados de países latinoamericanos en Madrid, se subrayó la importancia que tenían los medios de comunicación orientados hacia los inmigrantes: 
El periódico x tiene más fuerza entre el colectivo ecuatoriano, nuestros compatriotas, hay muchos que lo leen. Y este periódico está compartiendo muchas cosas con los ecuatorianos, está adentro con los ecuatorianos, va a los sitios donde hay que estar, no cogen el teléfono diciendo "¿qué hay de noticias?”, y esas cositas van haciendo realmente nuestra realidad, la sensibilidad nuestra se va plasmando (Ecuatoriana. Líder asociativa, GD).

Yo quiero tratar de hallar el porqué de la aparición de los medios de comunicación en España. Pretendo aproximarme en el sentido de que ni las radios, ni las cadenas de televisión, ni los periódicos han dado una cobertura suficiente al tema de la migración, como los compañeros han expresado, por razones de carácter financiero y comercial. El tema de la migración no les reportaba un anuncio más al periódico ni al canal de televisión. Hasta esta fecha los medios de comunicación no son abiertos del todo... Eso indica que el espacio reducido que se dedica a la migración genera un espacio de exclusión informativa, que todos los hombres tenemos el derecho a ser informados para ser libres. Entonces, no estoy queriendo poner toda la responsabilidad social sobre los medios españoles, simplemente creo que se ha actuado hasta la fecha con demasiado egoísmo y demasiado menosprecio al inmigrante. Pero los medios alternativos que están surgiendo justamente están queriendo compensar esa deuda informativa que se tenía en el ámbito de la migración (Boliviano. Líder asociativo, GD).

Aunque las primeras iniciativas responden a un interés por cuestionar y complementar la prensa generalista en relación a su cobertura de los temas que interesan a los inmigrantes, es preciso entender estos medios dentro de la dinámica específica del campo mediático como sector empresarial. Como hemos visto en la sección anterior, la particular ascendencia de los medios de comunicación sobre otros campos de producción simbólica de conocimiento y su declarada autonomía, basada en la profesionalidad de la búsqueda de la información veraz, dependen cada vez más de los intereses comerciales, económicos y políticos de los holdings mediáticos. La investigación específica del campo periodístico muestra como la ampliación y diversificación de ofertas mediáticas responde a la búsqueda y creación de nuevas "audiencias" con intereses específicos (Marchetti, 2005). En los kioscos de prensa encontramos hoy una infinidad de ofertas específicas, orientadas hacia el público femenino, juvenil, deportivo, etc., como parte de una estrategia de descentralización característica del capitalismo tardío que, bajo la apariencia de responder a intereses previos al mercado, los construye para su propia reproducción (Harvey, 1989).

Las fuerzas económicas que producen la fragmentación de audiencias son el contexto necesario desde donde explicar el nacimiento de estos medios, aunque se tenía que crear el contexto de oportunidad adecuado para ello. A pesar del crecimiento de la población inmigrante, se constataba que muchos de sus intereses específicos no los trataban los medios (Aierbe, 2003; Casero, 2004; Gualda et al., 2004; Pérez, 2003; Torregrosa, 2005). Se vivió hasta comienzos del nuevo siglo una acentuada sensación de exclusión mediática, que se trató extensamente por investigadores del equipo, como Retis, en su trabajo con los colectivos de origen latinoamericano (2008). En nuestro trabajo etnográfico fue evidente que el rechazo 
o la invisibilización de las especificidades de los inmigrantes impregnaban la sociedad civil y mediática. Todos los profesionales de revistas pioneras en este campo nos describían lo difícil que resultó crear interés entre comerciales de publicidad por acercarse a este tipo de empresas mediáticas. Los inmigrantes tenían aún que consolidarse como una audiencia creíble, y para eso fue necesario que cambiara el imaginario sobre los inmigrantes como personas pobres e ignorantes que realizaban sólo los trabajos no deseados por los españoles.

En efecto, la creación de una "audiencia" potencial para los medios no es un proceso "natural" derivado de la existencia física de un colectivo, sino el hecho de que este colectivo funja como productor y consumidor. Durante los últimos años la inmigración ha dejado de ser sólo mano de obra para constituirse como empresarios y consumidores gracias a su capacidad de aprovechar el crecimiento económico en España. Nuevas empresas impulsadas por los inmigrantes comienzan a partir de los pasados años 90 a transformar el paisaje urbano, especialmente aquellos barrios con alta concentración de inmigrantes, como los icónicos Raval, en Barcelona, o Lavapiés, en Madrid (Solé et al., 2007). Muchas arrancan sus negocios aprovechando el "mercado de la nostalgia", o bien sus necesidades más evidentes. Paralelamente, los inmigrantes asalariados habían superado las primeras etapas de asentamiento y contaban con dinero para gastar, más allá de lo básico (Santamarina, 2005). La demanda de los inmigrantes de productos específicos comienza pronto a ser evidente $\mathrm{y}$, aunque tiene importancia, el florecimiento de las empresas mediáticas orientadas hacia los inmigrantes no se genera a partir de la publicidad que buscaban las nuevas iniciativas de negocios mal denominados "étnicos" (Suárez Navaz, Gómez y Arco, 2012). Son las grandes empresas, en su expansión de marketing hacia los nuevos "consumidores" inmigrantes, las que dan el respaldo económico determinante a las nuevas iniciativas mediáticas. Grandes remesadoras transnacionales - Money Grant, Western Union-, bancos españoles - Banco de Santander, la Caixa, Caja Madrid, Banco Popular-, compañías telefónicas y grandes supermercados -El Corte Inglés o Carrefour - se unen a una enorme y diversa cartera de negocios, específicamente orientados hacia los inmigrantes en su búsqueda de publicidad - compañías de seguros, bufetes de abogados, escuelas de conducción, espectáculos y un largo etc.-.

Aunque este contexto económico es determinante, las nuevas iniciativas mediáticas justifican su aparición a partir de su función político-mediática, como parte de una necesaria lucha contra la exclusión y estigmatización de la inmigración en los países de destino. Las palabras de los profesionales de los medios así lo reiteran:

El objetivo era servir de comunicación porque además la ausencia de noticias latinoamericanas en los medios de tirada nacional era y es, todavía hoy en día, 15 años después sigue siendo tan grande, ¿no? En aquel tiempo la única manera de que era posible aparecer en un periódico, para un país latinoamericano era si habían descubierto un alijo de droga importante, si había habido alguna tragedia, que Pinochet todavía no quería soltar el gobierno, o que pasaba esto, o que los Derechos Humanos, en fin, sólo hechos luctuosos, sólo hechos que fueran tremendamente sensacionalistas. De ninguna manera había noticias referidas a la cultura o a las 
cosas buenas que se supone tenemos todos los países. La idea era, pues, crear un medio que, de alguna manera, diera importancia a este tipo de noticias (Juan Ignacio Vera, director de Euromundo Latino).

Nosotros siempre hemos destacado las cosas positivas de la gente y reflejado nuestra gente tal cual es, no hemos intentado usar photoshop para embellecer a las caras de los latinos, hemos intentado planchar la camisa en las fotos, ni nada, tal cual es la gente la hemos sacado, eso es lo que tenemos, es nuestro mundo, eso es lo que hay, ¿no?, destacamos las cosas positivas de la gente, nunca publicamos por ejemplo asesinatos, robos, eso se lee en la prensa nacional, ¿no? (José Luis Salvatierra, Ocio Latino).

Hemos querido buscar una forma para presentar las noticias africanas desde una perspectiva netamente africana. Estamos cansados de escuchar cómo otros relatan nuestras noticias de forma torcida. Y cuando el observador se convierte en relatador, es distinto a que lo cuente uno que en realidad forma parte de esa historia. Y como formamos parte de las historias que contamos, creemos de que somos capaces de ofrecer una visión más equilibrada, contraria a los que observan la historia, ni siquiera desde cerca, sino de larga distancia (African Bulletin).

Buscamos dar el espacio a los latinos en general y que tengan un medio de comunicación a través del cual hacer escuchar su voz... Nosotros queremos ser el medio de comunicación, que brinde la oportunidad y la posibilidad de que el ciudadano emigrante sudamericano tenga dónde expresar su criterio, criterio que tiene que ser ecuánime, centrado, pero su criterio al fin (José Vicente Checa, La Superlatina).

[Lo que nos distingue] es el compromiso..., lo que en algún momento puede darnos la nota es que el oyente se sienta representado, con una radio que vela porque, al menos, su voz se escuche (Álvaro Hernández, La Nuestra FM).

Es evidente que la aparición masiva de los medios orientados hacia los inmigrantes no sólo depende del contexto de oportunidad económica, sin la cual, sin embargo, hubiera sido inviable tal explosión de iniciativas mediáticas. La construcción de la audiencia por los periodistas inmigrantes está impregnada de protesta y reivindicación frente a las políticas de representación dominantes en la esfera mediática española. Hay una clara conciencia de intervención contra la discriminación y el racismo entre estos periodistas de origen extranjero y una idea de que el espacio mediático es protagonista en esta batalla.

\section{La construcción de las audiencias "latinas": contenido y recepción}

El análisis del contenido que prevalece en los medios dirigidos hacia los latinoamericanos afincados en España nos permite destacar tres aspectos fundamentales. Por una parte, se halla la construcción de los colectivos inmigrantes bajo las condiciones jurídicas y socioeconómicas de una fuerza de trabajo llegada recientemente. Por otra, están el ámbito de cobertura transnacional de la noticias, y finalmente, el énfasis en una identidad cultural diferenciada. Uno de los ejes de investigación del proyecto se ha centrado en el análisis específico y comparado de las políticas de 
representación en torno al fenómeno migratorio, a través del análisis de contenido en medios generalistas y específicos: ¿de qué modo se construye la "audiencia" en estos medios y cómo contrasta con la ofertada por los medios generalistas?, ¿en qué medida encontramos divergencias en el tratamiento de las noticias y en la representación de los inmigrantes entre unos y otros?, ¿cuáles son los rasgos predominantes en esta representación y de qué modo alcanza su potencial audiencia?

En este trabajo de análisis de contenido de los nuevos medios dirigidos hacia los colectivos inmigrantes hemos realizado una explotación de las noticias aparecidas en los dos medios con mayor tirada, Si se Puede y Latino, con una dimensión comparativa con los medios de comunicación generalista — El País y La Vanguardia - a través de la metodología ya establecida por el equipo de investigación de Mugak, que lleva años analizando sistemáticamente la cobertura de prensa del tema migratorio y que participa en nuestra investigación de forma activa. Paralelamente, se realizaba trabajo etnográfico con los colectivos hacia los que estos medios iban dirigidos, con cinco tesis doctorales que incorporaron la dimensión mediática de manera transversal en sus análisis más generales de los procesos identitarios y políticos de colectivos de origen latinoamericano y marroquí desde una perspectiva transnacional ${ }^{3}$. Adicionalmente, en 2007-08 y de nuevo en 2011, se han realizado entrevistas en profundidad con los 40 medios de comunicación más destacados en el panorama mediático orientado hacia los ciudadanos de origen extranjero en nuestro país. Finalmente, hemos explorado de manera sistemática con distintos grupos de discusión la opinión que sobre estos medios de comunicación tienen mujeres y hombres inmigrantes, jóvenes, y dirigentes de las principales asociaciones de inmigrantes en nuestro país.

Aunque los resultados son preliminares, encontramos tres grandes rasgos que definen la cobertura periodística y nos ayudan a explorar la específica construcción de una audiencia de "inmigrantes latinos" en estos medios. El primero de los temas recurrentes gira en torno a la especificidad migratoria. Gran parte del contenido de estos medios se dirige a informar sobre los procesos jurídicos relacionados con la compleja trama de adquisición y renovación de la documentación de extranjería, la reagrupación familiar, los procesos de retorno, y las políticas de inmigración de los partidos políticos españoles. Este tipo de información se considera crucial para alcanzar a "la comunidad", como a menudo se refieren a su potencial audiencia. Los distintos tintes políticos son muy claros, al igual que el de los medios generalistas, aunque se coincide en una visión sobre los problemas de los inmigrantes, que asigna la principal responsabilidad de éstos a los obstáculos que encuentran en el proceso migratorio.

${ }^{3}$ Los trabajos de Alicia Ferrández, Lucía Echevarría, Grégory Dallemagne, Nancy Wence, y Marisa Ruiz aportan análisis particulares, desde una perspectiva transnacional, sobre, respectivamente, los medios de comunicación "latinos" en Madrid y Londres, las mujeres y hombres jóvenes de origen marroquí, el colectivo ecuatoriano de una comunidad quiteña desde la perspectiva de sus jóvenes, el colectivo boliviano en Madrid, e iniciativas mediáticas alternativas, memoria e identidad (Suárez Navaz et al., en prensa). 
El análisis pormenorizado que hemos realizado sobre los dos periódicos más importantes en este ámbito, y su contraste con el tratamiento informativo de la inmigración en medios generalistas apuntan, no obstante, a un común recurso a fuentes informativas institucionales y al uso de una única fuente. Este tratamiento informativo, si bien adquiere en los medios de inmigrantes un tono crítico, lo aleja de un periodismo, que contrata las fuentes e incorpora un análisis crítico de los discursos oficiales sobre la inmigración. Se incorporan, eso si, en mayor medida, los testimonios de inmigrantes - un 16,4\% frente a un $11,6 \%$ - pero más como individuos que como declaraciones generadas por el movimiento asociativo - un $6,1 \%$, que en los medios generalistas desciende hasta un 1,6\%-. En suma, se critica la falta de información en la que están sumidos los inmigrantes, pero en gran medida se reproducen sus orígenes, el ámbito gubernamental. En los medios de inmigrantes aparece también el discurso de las autoridades de los países de origen, lo cual introduce una visión transnacional de las diferentes posiciones estatales, pero no contribuye substancialmente a generar una información alternativa a la oficial.

Es interesante explorar qué sucede cuando la fuente principal pasa a ser el propio inmigrante. En base a las manifestaciones realizadas anteriormente, deberíamos esperar una presencia fuerte de sus historias de vida o de proyectos e iniciativas surgidos en el ámbito migrante. Pero encontramos que casi la mitad de estos testimonios alude a problemas o al efecto de la actuación de las instituciones sobre determinadas situaciones. El tono es fundamentalmente crítico en casi un $60 \%$ de los testimonios, moderado o descriptivo en un $27,7 \%$, y con propuestas alternativas en un 18,4\%. En conclusión, la imagen de la situación de los inmigrantes se encuentra también en estos medios vinculada a problemas y conflictos, lo cual nos aleja de una representación normalizada (Martínez Corcuera y Aguirre 2011). O quizás nos acercan de una manera un tanto problemática además de problematizada, eso si, a las duras condiciones cotidianas vividas por todos los extranjeros en España.

En este sentido, aunque la representación de los "problemas" de los inmigrantes sea una de las médulas espinales de su imagen en estos medios y las fuentes de información disten de presentar un tratamiento de la noticia alternativo, el punto de vista que se escoge contrarresta el miserabilismo o la criminalización documentadas en las investigaciones que analizan la representación de la inmigración en los medios generalistas (Suárez y Fernández, 2011). En nuestras entrevistas y grupos de discusión aparece de forma rotunda la idea de que la exclusión de las personas de origen extranjero como profesionales en el espacio mediático español reproduce una visión hegemónica, interpretada a través de una frontera etnocultural: "Los ecuatorianos, o los latinos en general darían una visión alternativa de la inmigración, una visión que no enfatizara los problemas de los inmigrantes" (GD1. Madrid, 2007). Aunque esta visión simplifica y culturaliza la producción mediática, indica el modo en que la exclusión genera diferencia (Suárez, 2007).

Por otra parte, el trabajo de Alicia Ferrández, investigadora doctoral de nuestro equipo, ha mostrado, con su análisis cualitativo de la representación del inmigrante en su dimensión mediático-política, que existe una atención pormenorizada a los procesos políticos y jurídicos que atañen al colectivo en España y que le construyen 
como sujeto político: en su participación en las elecciones municipales, la reforma de la Ley de Extranjería, el paro, la educación, las redadadas y cupos de detención de los inmigrantes, o el pago de hipotecas (Fernández, 2011).

Aun así, nuestra investigación se desarrolla en los distintos planos del proceso de comunicación mediática, y es interesante ver cómo, desde el punto de vista del receptor, esta construcción de la audiencia bajo la categoría del "inmigrante" se problematiza y cuestiona, según observamos en el testimonio de una mujer ecuatoriana:

[los intereses de los inmigrantes] dependen más del momento en que esté, porque no tenía mi primera tarjeta, me interesaba sacar de donde sea esa información, pero ahora ya no. Se pierde el interés completamente" (GD con mujeres inmigrantes).

Cuando nos acercamos a la población joven, es mucho más evidente la discrepancia con la asunción de que el proceso migratorio define al colectivo. Los patrones de consumo mediático de los jóvenes y niños, descendientes de los inmigrantes residentes en España, tienen poco que ver con los de sus padres. Internet, las redes sociales como Facebook, Twiter o Tuenty, los chats y los teléfonos móviles son, al igual que para los jóvenes en general, su principal medio de comunicación. En el grupo de discusión dedicado a ellos y en las entrevistas realizadas, es evidente que no comparten la identidad "inmigrante" de sus padres, aunque conocen estos medios y los usan sobre todo para información de ocio "latino". Pero sus identidades múltiples, como hijos de inmigrantes, jóvenes, sujetos transnacionales y parte de las clases populares, les acercan a diversos y muy amplios medios específicos que rechazan la construcción de la audiencia "inmigrante" como base fundamental de su identidad.

El segundo de los rasgos definitorios de la audiencia en los medios es su dimensión transnacional. No hay medio que no incorpore de manera sustantiva la cobertura informativa de los países de origen. Las secciones dedicadas a los países de origen son, según manifestaba uno de los participantes, una "síntesis" de lo que ocurre en el país, pero se reconoce como complementaria de la falta de cobertura y del sesgo etnocéntrico percibido en los medios generalistas. En los periódicos analizados en profundidad encontramos más de un 33\% de noticias orientadas hacia la cobertura mediática del campo migratorio transnacional, frente a un $4 \%$ en los medios generalistas (Martínez Corcuera y Aguirre 2011) ${ }^{4}$. El componente transnacional de las políticas de representación de estos medios no se limita a la cobertura noticiosa de la situación política y económica o a las noticias deportivas o culturales. Los redactores utilizan activamente sus conexiones con el país de origen para documentar los aspectos que conocen que interesan a sus compatriotas, y la producción

${ }^{4}$ Distinguimos en nuestras categorías la cobertura "internacional" clásica de lo que denominamos "transnacional", orientado hacia la cobertura de noticias que vinculan origen y destino en su articulación a través de los procesos migratorios. Aunque a menudo se enfatiza uno entre los países de origen, - el de procedencia de la mayoría de inmigrantes a los que va dirigido el medio-, encontramos una dimensión transnacional mucho más compleja con multitud de referencias a los distintos enclaves de asentamiento del colectivo al que va dirigido el medio. 
financiera del medio abarca en ocasiones diferentes fuentes latinoamericanas o incluso norteamericanas. Se considera clave el capital simbólico de los periodistas latinoamericanos para dar una cobertura menos aséptica, no etnocéntrica, y trasladada a la audiencia en su propio "idioma", según vemos en el primer testimonio a continuación. A nivel periodístico, la producción de una cobertura transnacional demanda al periodista una elaboración diferente de lo noticioso que, como nos manifiesta el segundo testimonio, exigen, articulando a través de la cuestión migratoria, no sólo el país de origen y el de destino, sino el campo migratorio transnacional mediante el cual se modulan las noticias de los diversos enclaves de residencia de los migrantes.

En la parte editorial está, por lo mismo, un modelo editorial que creamos, un periodismo de cercanía, que emocione, que conmueva, que también haga reflexionar a la gente. Para eso hay que usar un lenguaje, que ya entrar a detallar lo que ya sabemos, que en nuestros países el lenguaje difiere un poco del español ibérico, y aún más, en cada país, pues, hay algunos giros, algún léxico diferente. El periódico, desde el punto de vista editorial, cuida mucho todos los detalles, tiene periodistas de distintos países, entonces saben cuidar esos detalles... esos periodistas latinos tienen la emotividad, la emoción, la capacidad de conectarse rápidamente con el público. Cuando se lee Latino en el lenguaje está muy claro la capacidad de contar lo que a ellos les conmueve, les atrae, les da esperanzas... el periódico es una cajita donde cabe todo, donde cabe las añoranzas, las tristezas, los sueños, las frustraciones pero también sus luchas, sus logros día a día, las cosas que le ayuden a ese crecimiento... editorialmente es eso. Cuando lees un periódico español porque hay frases ya hechas del lenguaje ibérico que no se usan en Latinoamérica, entonces no lo usamos para que el lector en ningún momento vaya a sentir que este es un periódico hecho por españoles para ellos, sino uno hecho por latinoamericanos para latinoamericanos, eso es clave (Director Revista).

[La situación de los periodistas en estos medios] es muy difícil porque uno tiene que satisfacer a la vez una audiencia en el país de origen y en destino. Uno tiene que elaborar un discurso sobre la migración que cubra la demanda informativa de ambos (Periodista y directivo, en grupo de discusión de dirigentes).

A falta de un análisis más detallado de este aspecto, es relevante señalar la reproducción del nacionalismo de origen en consonancia con lo que la literatura transnacional ha denominado "nacionalismo extraterritorial" (Fitzgerald, 2000; Suárez Navaz, 2010). Los mismos procesos de homogeneización que caracterizan al nacionalismo particular que se represente se reproducen así en el campo migratorio transnacional, con sus sesgos etnoraciales, de género y de clase social, entre otros (Cortez, 2004, para un análisis de caso ecuatoriano desde nuestro equipo de investigación). Así lo manifestaba en los grupos de discusión un periodista involucrado también en el mundo asociativo, en un interesante fragmento que indica el tipo de exotización que, en ocasiones, los medios reproducen:

R: Piensan primero que uno es de producción: uno les tiene que hacer el trabajo a ellos, y uno tiene que contestar lo que ellos quieren. Por ejemplo, vienen y 
"queremos saber cómo se festejan las bodas en Ecuador". Y yo les digo "como aquí”. Sí, no hay diferencia. Lo que pasa es que aquí hay más gasto, pero nada más, es lo mismo. Y ya empezamos con los tópicos. Y creo que es responsabilidad de nosotros hacia el Ecuador pedir el respeto que se merecen todos los grupos sociales en nuestro país. No dejar que se de una imagen... Para mí lo que se muestra del Ecuador, no es el Ecuador. El Ecuador no es eso. En Ecuador hay un 30\%, si no me equivoco, del 30 al 40\% de población indígena: cholos, negros, mestizos, blancos, mulatos...

W: Pero es que para las fotos de representación de Ecuador sale una ancianita, pobre, con su vestidura...

R: Y yo aceptaría eso cuando ese traje que está usando los usara siempre, que sea habitual, o sea, si yo visto así toda mi vida, pero para la foto he discrepado... En el momento en que se hace esta foto se da una imagen de país sufrido, el mito de la ecuatorianidad, como raza, los indígenas estamos en una situación en que prácticamente nos cogen y nos deshacen... Todo es verdad, ¡todo es verdad! Yo acepto que en día del Pase, el Pase del Niño, todos estemos ahí, y todos juntos vamos a festejar, todos los sectores... Pero no, ahora hay algo que la Comunidad de Madrid, o el Ayuntamiento de Madrid o quien sea, tiene intereses, y se nos va a retratar así. Entonces ese discurso... O como lo de los Latin King: éste lleva pantalones anchos, éste es un Latin King... Entonces yo digo que esos estereotipos que se están creando y que a veces los medios de comunicación también están ayudando a que salga eso. Entonces yo creo que en este tema hay que generar opinión, que no salga sólo eso... (GD dirigentes).

Este testimonio enlaza perfectamente con el tercer rasgo que quiero destacar en la construcción de las audiencias que empíricamente estamos trabajando en los medios orientados hacia los inmigrantes: el modo en que los medios contribuyen a la reproducción de nociones de "cultura común", basadas en rasgos identitarios dominantes y homogeneizadores. La "cultura" funge como elemento cohesionador de la audiencia, a través de una iconografía predominantemente nacionalista, identificada con expresiones culturales tradicionales como la religión, las celebraciones patrias, o los valores supuestamente compartidos por los latinoamericanos, como la familia o el papel de la mujer en ella. El concepto de cultura tiende a reproducir la división liberal entre lo público y lo privado, construyendo un imaginario de coexistencia multicultural donde los inmigrantes mantienen su "cultura" en el ámbito privado, mientras que se "integran" en la esfera pública a través del trabajo (Suárez Navaz, 2004; Collier, Maurer y Suárez Navaz, 1995).

Una lectura feminista del contenido de estos medios de comunicación como la realizada por las investigadoras de nuestro equipo, Lucía Echevarria y Sofía Bruquetas, desvela los efectos de esta noción prístina de cultura en la representación de las estructuras de género (2011). Las mujeres inmigrantes aparecen como sostenedoras y reproductoras del ámbito privado cultural en una representación dominante de la maternidad y la familia como espacio diferenciador de la cultura modernizadora europea. Es significativo que en el análisis cualitativo las mujeres que aparecen representadas en ámbitos laborales con capacidad de decisión son a 
menudo españolas, creando así un imaginario que tiende a reforzar la idea de que la integración de las mujeres implica un abandono del espacio doméstico a través del cual se reproduce la especificidad cultural. El recurso a las representaciones de una "cultura" compartida por la audiencia presenta un imaginario de la reproducción de la tradición patriarcal, donde las transformaciones de género producidas en los procesos migratorios son invisibilizadas o incluso representadas como disfuncionales.

En el trabajo de análisis de contenido, basado en datos cuantitativos, queda claro el dominio de la representación cultural nacional sobre todas las demás -un 56\% en Si se Puede, o un $62 \%$ en Latino, frente a un $11 \%$ de referencia pan-nacional en ambos medios - Según el trabajo del investigador de nuestro equipo, Grégory Dallemagne, la infravaloración de las referencias que denominamos "etnotribales" o regionales" se acentúa en estos medios a través de un uso comercial y superficial de las imágenes referidas a las comunidades indígenas, no encontrando apenas en la cobertura mediática de la presencia indígena en los procesos migratorios transnacionales ninguna referencia a las variables políticas o especificidades de sus trayectorias migratorias (Dallemagne, 2011).

Finalmente, encontramos una referencia transversal en las noticias a una "cultura común" de los latinoamericanos, basada en las prácticas religiosas y en identificadores culturales pan-nacionales que remiten al proceso colonizador español -ibérico- en América Latina. La idea de lo "latino", como nueva categoría que abarca a todos los herederos de la inmigración latinoamericana en España, es aún minoritaria, pero sin duda pujante. En su análisis de las representaciones culturales de los medios de/para inmigrantes, Dallemagne destaca dos ámbitos en los que esta referencia transversal es más destacada. Por una parte, subraya un imaginario vinculado a una "cultura pop" cosmopolita, que remite imágenes de personas de origen latinoamericano que han conseguido el éxito internacional con la marca "latina". Por otra parte, en referencia a los jóvenes, observa una resignificación del gentilicio usado de manera derogatoria o estigmatizante en la prensa generalista para referirse a las "bandas latinas", como los Latin King o los Ñetas.

No es casual, creemos, que sean estos ámbitos donde el imaginario de los "latino" prevalezca. La "cultura pop" latina, cristalizada en un espacio comercial transnacional con fuerte influencia norteamericana y donde las producciones culturales de la población de origen latinoamericano han adquirido una dimensión global, apela a una herencia musical común de boleros, bachatas, merengues, San Juanitos, rap, hip hop, y otras expresiones culturales, que han venido a redefinirse y revitalizarse en el contexto migratorio adquiriendo una "marca" propia en la industria cultural de masas. La lectura de esta "cultura pop" por Dallemagne es crítica, incorporando la visión de Horkheimer y Adorno en relación a la función legitimadora de las industrias culturales de masas con productos culturales, que hacen viable la reproducción del capitalismo burgués (Dallemagne, 2011). En este sentido, podríamos añadir que la categoría pan-nacional de "latino" o "hispanoamericano" aparece vinculada con fuerza a espacios institucionales y a una categorización aglutinadora de lo latinoamericano dominante en España, y que se destaca no ya sólo por su valor comercial, sino por su recreación de imaginarios coloniales, como la Feria de las 
Américas y las múltiples celebraciones locales del "día de Hispanidad", o día de la Raza, realizadas en España el 12 de Octubre para conmemorar la conquista de las Américas.

En mi opinión, también hay una dimensión empoderadora en la construcción de la nueva referencia cultural de "lo latino" en España. Por una parte, destaca el carácter poscolonial que la categoría adquiere en el entorno español, uniendo a todos los inmigrantes de origen latinoamericano frente al antiguo poder colonial y al actual país receptor donde se experimenta formas contemporáneas del racismo incrustado a través del sistema de castas en la estratificación latinoamericana y española. El trabajo etnográfico con diversos colectivos latinoamericanos avala la confluencia no sólo de su situación socioeconómica y legal, sino la convivencia cotidiana que los latinoamericanos establecen en sus patrones residenciales, espacios de socialización y prácticas culturales. Por otra parte, el estudio del proceso de autodenominación de los latinos en Estados Unidos, frente a la categoría propuesta en el censo oficial y las políticas públicas de "hispano", nos remite a una historia de concienciación y lucha compartida (Portes, 2006). Esta articulación se presenta de forma clara en la respuesta del director de Ocio Latino a la pregunta de porqué escogió este gentilicio:

Si, este, yo antes había viajado este a EE.UU, en EE.UU a los hispanos les dicen latinos no? entonces este a mi me llamaba mucho la atención porque allí todos éramos latinos y los españoles también eran latinos, pero decirle a los españoles latinos aquí en su propio país era prácticamente como decir no, nosotros no somos latinos, ustedes son hispanos y nosotros españoles, era como una división no? En cambio, en EE.UU todos eran inmigrantes, todos eran marginados, incluyendo los españoles, todos eran latinos. Entonces esa palabra latinos era una palabra que a mí me llamó mucho la atención precisamente porque unía en primer lugar, y, en segundo lugar, porque reivindicaba lo que mucho tiempo no han, no quisieron reconocer [los españoles], porque Latinoamérica no es una palabra de los españoles, es de los franceses, un poco para, para si quieres para fastidiar a los españoles no?, aparte de significar es como reivindicativo, entonces son esas dos cosas que por eso es que se eligió latino [como parte de la cabecera de la revista].

Teóricamente, lo interesante de este proceso es que nos exige separarnos de algunas visiones primordialistas de la etnicidad, en las que la base de la conciencia étnica debe responder a ciertos rasgos culturales objetivos como el idioma, la religión, el vínculo a un territorio común, etc. (Smith, 2000). En este caso, como en el fenómeno estadounidense, el marketing está indisolublemente unido al proceso de etnogénesis, sin restar a éste su enorme capacidad de empoderamiento, reivindicación, producción cultural e influencia política (Dávila, 2001, 2008). La teoría de campos de Bourdieu, además de una visión constructivista de la etnicidad, nos permite avanzar en este sentido y superar ciertas críticas comunes en nuestro entorno sobre la "realidad" del fenómeno de creación de lo "latino" en España.

En las representaciones que encontramos en los medios, el componente de lo "latino" remite a una experiencia común de migración, de estigmatización etnoracial, así como a una experiencia histórica compartida. De alguna manera, más allá de la reproducción de las representaciones hegemónicas de género y de etnoestratificación 
señaladas, lo "latino" aparece a menudo vinculado a procesos de mixtura cultural generada en el proceso migratorio. La referencia a elementos culturales compartidos a través de los colectivos latinoamericanos se expresa como una conciencia de "solidaridad latina" — nosotros - frente a la sociedad receptora — ellos, los "españoles/ europeos-y a la necesidad, en el contexto migratorio, de ir más allá del nacionalismo originario:

Nos interesa lo que pasa en Colombia, lo que pasa en Perú, porque aquí estamos todos viviendo juntos y nos gusta saber que es lo que les pasa a ellos. Creo que esto es también una buena integración entre nosotros. Y si un medio se define como latino, debería de serlo realmente, no lo que a veces vemos que hacen las revistas dividiendo por los países, Ecuador, Bolivia, Perú, Colombia, todos divididos. Eso no es latino (Mujer en el grupo de discusión de mujeres inmigrantes).

El 50\% de los inmigrantes nos dice que no se sienten integrados, ¿por qué?, porque a veces nuestros periódicos nos llevan a volver a lo nuestro. Vengan a jugar al fútbol, pero sólo entre ecuatorianos, vengan a comer, pero sólo comida ecuatoriana, vengan a divertirse, porque Julio Jaramillo está cantando. Así que creo que los medios están produciendo una doble segregación" (Hombre ecuatoriano, en el grupo de discusión de hombres inmigrantes).

Finalmente, el uso de lo "latino" sirve para redefinir la identificación cultural de los más jóvenes, entre quienes la fuerza del nacionalismo extraterritorial se debilita sin desaparecer, sin embargo, la conciencia de diferencia cultural frente a los españoles. Los periodistas nos manifiestan la dificultad de entender estos procesos culturales donde se redefinen los vínculos con los países de origen, así como las prácticas de consumo cultural, según lo manifiesta el director de Latino en una reciente entrevista:

De hecho, a nosotros nos cuesta mucho trabajar esa segunda generación básicamente porque aún no está, aún no está definida ¿no? Hay muchas incógnitas en esa segunda generación y hay incógnitas que justo ahora en EE.UU nos llevan como 30 años de ventaja en, en, migración, bueno de eso sabrás mucho mejor tu que yo, pero EE.UU es un referente sociológico como muy directo para nosotros ino?, pues aún no es eso[aquí]... si está evolucionando mucho, [pero] aún no está claro hacia dónde va y nosotros lo tratamos básicamente en Internet ... esa generación, en internet es mucho más fácil y de hecho [la versión del periódico en] internet está mucho mas pensada para esa segunda generación.

\section{Periodistas latinoamericanos y los retos de la democratización del espacio político-mediático en España}

La construcción de la audiencia alrededor de los ejes fundamentales señalados, - sus necesidades informativas como colectivo inmigrante, transnacional y culturalmente específico-, se desarrolla en un contexto de oportunidad estructuralmente dependiente de la creación de la "marca" que los identifica como población objetivo en términos mercadotécnicos. Los medios de comunicación crean y recrean 
imaginarios de pertenencia a colectivos específicos, cuyo mantenimiento y reproducción ideológica y material se convierten en instrumentales para la mercantilización de los medios.

Bourdieu nos alerta sobre los efectos sociopolíticos del dominio de intereses económicos en el campo periodístico, en el que, más que innovar, se busca acomodarse en el cliché hegemónico

a través de un proceso en el cual las estructuras sociales de poder se reproducen con visiones del mundo compatibles, un proceso que está profundamente descentralizado, abierto a contradicciones y conflictos, pero en general sumamente efectivo... [reproduciendo] el universo de presuposiciones tácitas que aceptamos como nativos de una determinada sociedad (Bourdieu, 2005: 37).

Las lógicas de creación de lo "noticioso" se vinculan a objetivos comerciales que pasan a ser centrales en las variables que definen a un buen periodista. No obstante, en el caso de medios como los orientados hacia los inmigrantes o los latinos, la importancia de un periodismo comprometido con la situación de exclusión mediática en el país receptor pasa, como hemos visto, a un primer término. Ésta es una de las primeras contradicciones que viven los periodistas latinoamericanos, contratados para construir un medio orientado hacia las nuevas minorías.

Como afirma Marchetti, la "identidad dividida" es un rasgo característico de los profesionales que trabajan en los medios de minorías: "los periodistas son estigmatizados en el campo periodístico como cooptados por sus fuentes, o incluso como portavoces de las mismas [más que como profesionales] se les tacha de 'activistas" (2006: 67). En las entrevistas a periodistas latinoamericanos surge esta "identidad dividida" con fuerza: son reclutados específicamente por su conexión a, y conocimiento de, los colectivos que fungen como audiencia potencial. Su capital simbólico es una pieza clave en la competitividad del sector: son los principales artesanos de las estrategias de producción del hecho "noticioso", pero también en las estrategias de distribución entre los inmigrantes e incluso en la captación de publicidad específica. Su prestigio como periodistas depende en gran medida de su capacidad de mantener, crear y redefinir los intereses de los colectivos inmigrantes.

Por otra parte, la estigmatización como periodistas "étnicos" debe ser compensada con un ejercicio profesional depurado a nivel técnico para ganar credibilidad frente a las empresas mediáticas y los colegas de profesión. Las estructuras económicas del campo periodístico les coloca en una posición marginal, reforzada por la inestabilidad legal y el estigma etnocultural que comparten con los colectivos inmigrantes, pese a que por su formación y trayectoria laboral previa pertenecen a una clase media, que les diferencia de la mayoría de los trabajadores latinoamericanos no cualificados. En el campo periodístico, los profesionales de origen extranjero realizan su trabajo en unas condiciones laborales más precarias que las de sus colegas españoles, lo cual se traduce en una escasez de recursos, endémica en los medios orientados hacia los inmigrantes, y una dificultad para realizar su labor profesional.

Husband ha mostrado en su trabajo con periodistas de minorías en Gran Bretaña cómo esta "identidad dividida" marca sus prácticas profesionales e identitarias 
y destaca la importancia de explorar cómo reconcilian "su compromiso con una identidad profesional y su estatus con la negociación de su propia identidad étnica" (2005: 1). En relación a este dilema y según lo encontrado en la investigación, proponemos tres tipos ideales, siguiendo a Weber con cautela epistemológica, como "herramientas metodológicas y que, por tanto, no deben implicar de ninguna forma la idea de que la vida está dominada por consideraciones racionales" (1978: 10). Se trata, por consiguiente, de construcciones lógicas derivadas de la combinación de una serie de variables sobre el tipo de empresa mediática, que contrata al periodista, y la atribución por éste a su quehacer periodístico de una serie de significados de tipo subjetivo.

En primer, lugar encontramos un perfil en el que el periodista se encuentra cómodo en las lógicas mercantiles que prevalecen en las empresas mediáticas. Este primer tipo podría denominarse instrumental, donde el vínculo personal del periodista con la población objeto o audiencia se desplaza frente a las dinámicas profesionales desarrolladas en la empresa. Este periodismo adapta el trabajo de construcción de lo noticioso a las variables mercadotécnicas. Tiene una mayor capacidad para externalizar las funciones de distribución y captación de publicidad y, como norma, es iniciativa de grupos empresariales más amplios. La audiencia potencial se concibe en términos económicos, como grupo consumidor:

En estos momento las empresas españolas están poniendo los ojos en nosotros por distintos fines, es un mercado nuevo digamos, muchas veces el mercado español ya está, no digamos quemado, pero ya está explorado, pero nosotros somos tierra virgen para ellos, entonces el mercado español en estos momentos está apostando bastante fuerte por los medios latinos... porque nosotros somos un mercado que básicamente está por explorar... porque tenemos mejor o igual capacidad de compra que el español.

Hay que tratar de tener un medio de comunicación, eso te ayuda mucho, te abre puertas, para negocios, para muchas historias, a nivel político también te ayuda mucho, ya, pero lo único que yo te podría decir es para poder subsistir ante unos tiburones grandísimos que hay en estos momentos devorándose, lo que es la plaza de la inversión en medios de comunicación hay que inventarse otras historias, sacar otros medios o profesionalizarse en determinado sector.

Lo que estamos haciendo es un producto, en el lenguaje comercial, en este caso muy caro, hay que pagar muchos sueldos, mucha gente, mucho papel, queremos subir a cuarto de millón en este año [de tirada]... crecemos y seguimos creciendo, nuestro objetivo es seguir creciendo a toda España, ... la inmigración que seguirá durante muchos años en España y eso da pie para seguir creciendo... metes un anuncio en una página que cuesta 6.000 euros, nacional, pero te van a ver 600.000 personas... a nosotros nos da igual de dónde sea la publicidad, que sea del Ministerio de Educación o de la Coca Cola, es publicidad.

Nuestra intención fue crear un medio de comunicación que fuese capaz de llegar de una forma, digamos rápida y masiva a los colectivos de inmigrantes, ¿no? Y eso fue como la idea inicial. A partir de allí fuimos delimitando más los colectivos, o sea, el 
colectivo al que nos queríamos dirigir hasta quedarnos con el colectivo latinoamericano por razones... primero, por razones de sentido comercial en el sentido en que el colectivo latinoamericano es el único que puede formar un colectivo lector o un nicho de mercado con un peso suficiente como para poder atraer, pues lo que es la otra parte de una empresa de comunicación que es la publicidad ... el mercado de la publicidad siempre es un mercado muy complicado, es muy conservador y a veces no guía sus decisiones por criterios tan racionales como nos gustaría a todos. Pero, sin embargo, la inmigración ha crecido tanto que y han mejorado tanto... que se ha convertido en un nicho estratégico para casi todas las marcas en casi todos los sectores de la economía española. Y eso obviamente ha ayudado y eso es lo que nosotros habíamos previsto que iba a pasar de alguna forma, ¿no? Y al final pasó.

El segundo tipo ideal lo hemos denominado clientelar, siguiendo el enfoque antropológico de estudios del Mediterráneo y América Latina, pero incorporando las críticas surgidas a una lectura del patronazgo como cultura política característica de sociedades con un Estado poco desarrollado, en las que sus elites buscaban perpetuar sus intereses a través del clientelismo local y culturalmente arraigado (Gellner y Waterbury, 1977). El trabajo de Silverman desestima la idea de una cultura política y describe el sistema clientelar como una característica estructura social que "facilita el acceso discriminado a los bienes deseados", según expresa el tercer testimonio más abajo (1977). Este perfil de periodismo combina su ejercicio con la ampliación de los contactos personales dentro de los colectivos de inmigrantes. En este perfil, el papel del periodista está mucho más volcado en el desarrollo de una base sociológica firme, que garantice la supervivencia del medio a través de la inclusión de anuncios de pequeños comercios en general, impulsados por empresarios surgidos de colectivos inmigrantes o fuertemente dependientes de los servicios ofrecidos hacia ellos. En estas iniciativas mediáticas, la figura del periodista está más estrechamente vinculada a su capacidad para crear lazos de confianza con los anunciantes y tener los contactos adecuados para facilitar su distribución en los más diversos espacios de socialización inmigrante. Frente a las más poderosas iniciativas mediáticas, el grueso de los periodistas son freelance y/o voluntarios.

[A]l poner en funcionamiento una revista, al no tener dinero ni patrocinador, había que ir a buscar anunciantes. Esta es una revista actualmente financiada por los anunciantes, por la gente de la comunidad. La publicidad, la publicidad de los argentinos de aquí: restaurantes, productos médicos, en fin; o sea, los anunciantes que tú vas a ver en la revista son los que financian la revista. Pero, como te puedo decir, no es una revista que sea un negocio rentable, no es un negocio, esta revista no es negocio, yo que soy un loco, [aunque] no me da pérdidas.

Las relaciones son de alguna forma clientelares, es decir, nosotros ayudamos y ellos nos piden ayuda, esto es muy común, tenemos campañas publicitarias, hacemos que se les conozca, les presentamos a un buen abogado y asi las asociaciones pueden crecer, esto es, les ayudamos en los que podemos.

Si tengo un amigo periodista, es más fácil que tus actividades lleguen a conocerse. Así que no es sólo un estándar profesional por informar lo que interesa a todo el 
mundo, porque cada asociación, cada institución tiene proyectos, programas, todos están intentando introducirse en el sistema en el que nos movemos.

El tercer tipo ideal lo hemos denominado, siguiendo la terminología gramsciana, orgánico. Se trata de un periodismo que prioriza el papel del periodista como intelectual orgánico en un contexto de exclusión político-mediática. Este tipo de periodismo es minoritario, con poca cabida en las empresas mediáticas, especialmente en la prensa escrita. La radio genera una posibilidad diferente de establecer vínculos directos con la audiencia, especialmente aquella que se define como radio comunitaria. El objetivo periodístico es de una manera mucho más clara servir de vehículo a la expresión de los intereses del colectivo inmigrante, tanto a nivel informativo como para favorecer procesos de concienciación y participación asociativa. El formato elegido es similar al periodismo de cercanía o periodismo local, con menos intervención del proceso técnico de construcción de lo "noticioso":

Pues esta es una radio, yo diría que absolutamente aperturista, plural, comprometida, reivindicativa, y con una tendencia a defender lo público, la constitución y la ley, y también los derechos ciudadanos. Si lo sintetizamos es eso. Creemos en el Estado de derecho, eso es, defendemos la democracia hasta donde nos den, y también defendemos los derechos de las personas, de todas las personas, y más aún si se está atentando contra los derechos de los más débiles. Hay reparos enormes que nosotros tenemos sobre la ley de extranjería, sobre los centros de internamiento, sobre el trato maniqueo de la Unión Europea en este tipo de temas...Y creo que somos una radio necesaria en el momento actual de Europa, donde la extrema derecha gana en Italia..., en Francia se restringe también el derecho a vivir en familia, a nosotros los inmigrantes se nos restringe, porque sí, y es un derecho, todo el mundo quiere vivir en familia. Entonces esta radio quiere hacerse eco de ese sentir. Nosotros no vamos a dejar de sentir como inmigrantes, está claro. [Cuando empecé] en la radio latina no había un programa realmente periodístico, sino que era de cachondeo. Yo les dije "me quedo pero yo voy a hacer un programa periodístico, yo creo que la gente está madura, la gente pide información, asesoría". La primera semana se retiraron 2 clientes, entonces se hacía complicada la cosa, pero yo seguía teniendo audiencia..., tenía el $72 \%$ de audiencia de la franja de la mañana de todas las radios latinas.

Entonces, de qué estamos observando: de que los medios de comunicación social están buscando la noticia como tal, no están proporcionando un marco informativo, aquellos que no somos noticias somos excluidos de los medios de comunicación latinos, y eso no puede ser. Muchas veces no puedes dar una opinión que puede generar otra opinión. Lamentablemente, con esto quiero cerrar, no estamos representados en los medios de comunicación, ni en los espacios de televisión ni mucho menos en las radios... ¿Por qué tanta marginación? Nos están tratando poco más que como a mendigos, nos dan migajas de espacios en la radio, no puede ser...

No debemos perdernos de vista, creo que el objetivo está claro: ellos apuntan a un periodismo comercial, nada más, que la noticia debe tener un impacto en la sociedad, qué sé yo... Como ustedes dicen en términos periodísticos, hay que vender. Creo que los medios de comunicación social, en el tema de la migración, van en 
la línea puramente comercial, porque la pregunta es, quién va a percibir beneficio, estrictamente, de que la noticia tenga el máximo impacto posible. Para equilibrar, digamos, ese periodismo sensacionalista, yo creo que las organizaciones tendremos que hacer esfuerzos; es más, mi asociación ha conseguido unos fondos para sacar su propio periódico, porque no hay, porque definitivamente los medios clásicos se están lucrando con el tema de la inmigración, y además están marginando a los compañeros protagonistas de la noticia, sólo por la óptica subjetiva de todo periodista: "no, yo creo que ahí no me sale una noticia", pero no es tanto así... La responsabilidad del periodista es también social, no es enteramente comercial.

\section{A modo de conclusión}

La antropología ofrece una visión integral de los fenómenos sociales, de su dimensión simbólico-política, y del modo en que las fuerzas estructurales de tipo macro económico globalizadas configuran nuevas estrategias y subjetividades. El impacto de la globalización en la disciplina ha producido una reflexión teórico-metodológica sustantiva, con cientos de reflexiones sobre el modo en que el quehacer etnográfico se viene transformando para explicar y dar cuenta de las transformaciones culturales y sociopolíticas de los agentes sociales. En el campo migratorio, el trabajo sobre la condición migrante debe ser cauteloso y no dejarse atrapar por los imaginarios dominantes restrictivos, que presentan la inmigración en términos económicistas y laborales o culturalistas. Transformaciones más generales del modo de producción, con la radical importancia de la dimensión mediática y el creciente relieve del espacio transnacional en nuestra cotidianidad, deben incorporarse a nuestra comprensión de los fenómenos de movilidad y mediación cultural.

Por otra parte, los estudios migratorios tienen que dejar atrás la concepción del inmigrante como mano de obra no cualificada y su polarización con la inmigración de elite, lo que la Ley ha denominado, "los dueños del universo" (2004). La nueva demografía social de la movilidad transnacional incorpora colectivos fuertemente cualificados, una clase media cosmopolita que abarca en sus trayectorias personales y profesionales el mundo desarrollado: "Emergen todo tipo de esquemas y tipos y redes transnacionales de profesionales expatriados, que pueden tener un papel efectivo en el desarrollo de su país - incluso sin un retorno físico temporal o permanente_-". Es lo denominado por Meyer y Brown "trabajo cooperativo distante" dentro de una diáspora intelectual. Aunque estos vínculos siempre existieron de una u otra manera, son ahora sistemáticos, densos y múltiples (Vertovec, 2005: 7-8).

El estudio de los medios de comunicación orientados hacia los inmigrantes no debe ser un objeto de estudio en sí mismo, como hemos mantenido, sino un objeto de observación a través del cual exploramos procesos de transformación más amplios sobre el tipo de cultura política desde la que se construye el modelo de ciudadanía. Los medios, en este sentido, son un espacio etnográfico privilegiado para explorar, como proponen Boyer y Hannerz, los retos a los que nos enfrentamos "los intelectuales profesionales y nuestras culturas disciplinarias especializadas en un momento de intensa mercantilización, innovación comunicativa y el aumento relevante de nuestras relaciones sociales translocales" (2006: 6). La antropología 
comparte con el quehacer periodístico muchas perplejidades y descontentos, más allá de que evidentemente, el espacio mediático configure nuestros objetos de estudio de una forma central. En el caso del estudio antropológico de las migraciones, la incorporación de profesionales extranjeros, situados en nuestro mismo nivel de formación, no sólo incorpora una visión de la extranjería radicalmente alejada de los imaginarios de "alteridad", reproducidos en algunas visiones empiricistas de los procesos migratorios, sino que nos acerca de modo reflexivo a las condiciones de producción del conocimiento en el que como académicos estamos inmersos. El estudio de las políticas de representación en el entorno migratorio, por tanto, está indisolublemente unido a un proyecto antropológico, epistemológicamente reflexivo sobre nuestras propias prácticas de representación en la "ecumene global" (Appadurai, 1996; Hannerz 1992).

El análisis de los medios ha exigido en nuestra investigación considerarlos instrumentos de la capacidad humana de representación simbólica y política, claves en la configuración del espacio público, y a la vez comprenderlos como profundamente condicionados por las tecnologías sociales y la "ecología de los propios medios" (Boyer, 2006; Luhmann, 2000; Mcluhan, 1964). Como antropólogos dedicados al estudio de las migraciones internacionales, además, hemos incorporado nuestro trabajo etnográfico de observación participante y multisituado a través de las redes que configuran el campo migratorio transnacional. Apuntábamos, por tanto, a una consideración de los inmigrantes como sujeto de estudio, que adquiría un profunda heterogeneidad de clase y una dimensión transnacional, un análisis de las condiciones de posibilidad de la transformación del espacio público desde la producción y la recepción de lo mediático en nuestro país. Así, el contexto local español adquiere una gran relevancia en la comprensión de las fuentes, estructuras y actividades del poder, en los procesos de comunicación política y construcción democrática.

Una de las conclusiones del estudio nos ayuda a entender el modo en que el racismo y la exclusión van más allá de los procesos de discriminación y exclusión característicos de la estructura de clases sociales. Éste es, a mi entender, un aspecto crucial para abordar críticamente la herencia colonial que de forma diversa experimentan profesionales, estudiantes y residentes extranjeros en nuestro país. Los procesos de exclusión mediática, estudiados en nuestro entorno a partir del análisis de la prensa generalista, de la publicidad, o de otros espacios mediáticos, como la producción cultural industrial en nuestro país, se extienden además a la forma en que las empresas mediáticas y las industrias culturales excluyen laboralmente a extranjeros cualificados. Según han subrayado otros trabajos a nivel internacional, "se muestra cómo la movilidad social y espacial acelerada, basada en la medición 'universal' del talento y la capacidades no se traduce de hecho en la eliminación del desafío de la incorporación. La cultura y el modo particularista de entender el "know how" impone dificultades de integración de este tipo de inmigrantes [profesionales cualificados]" (Favell et al., 2008: 17). El proceso de democratización de nuestro espacio político-mediático y de nuestro propio espacio académico y antropológico, requiere, por tanto, mucha intervención y análisis crítico, que está por llegar. 
Otra de las conclusiones que emanan de nuestro trabajo de investigación es una reflexión sobre los procesos de translocalización y cosmopolitismo, que se desprende de la etnografía entre periodistas e/o inmigrantes. Como ciudadanos inmersos en flujos de información globales, estamos acostumbrados a conocer el "mundo" a través de las noticias manufacturadas por los holdings mediáticos y, cada vez más, mediante formas alternativas de comunicación social vinculadas o no al ejercicio periodístico. La construcción de nuestra visión del mundo social es producto de luchas por la imposición de un principio de visión y división, como mantiene Bourdieu, en el que el espacio mediático es fundamental. El cosmopolitismo derivado de esta coyuntura económica, tecnológica y sociocultural no es privativo de las clases dominantes, y la antropología ocupa una posición privilegiada para explorar el modo en que diversos colectivos incorporan una "ecumene global", así como sobre sus efectos en nuestras estructuras políticas y nuestro proyecto democratizador.

El transnacionalismo que se adjetiva de los migrantes no es privativo de ellos, pero descubrimos a través de la investigación la riqueza, densidad y variedad del consumo mediático de estas poblaciones, que operan a través de sus redes sociales y circuitos de información. El espacio mediático, cada vez más diverso, diversificado y especializado, incorpora no sólo agentes sociales nacionales, sino también internacionales y transnacionales, configurando lo que Fazal y Tsagarousianou han denominado "el espacio mediático diaspórico" (2002). Este espacio incorpora a menudo medios del país de origen, los canales internacionales de satélite y los nuevos medios de minorías o inmigrantes, además de los recursos online de cualquier rincón del mundo. Es un paisaje de flujos múltiples y multidireccionales de información, entretenimiento y producción cultural, que es preciso incorporar al estudio de las relaciones interétnicas y los procesos identitarios y políticos en la base de la trasformación de nuestras sociedades. El estudio de la "cultura" desde la perspectiva antropológica en este espacio globalizado requiere, al menos, de grandes dosis de humildad y una profunda renovación de nuestros presupuestos teóricos y metodológicos.

\section{Referencias bibliográficas}

AIERBE, Peio

2003 "Inmigración: los medios de comunicación, creadores de opinión pública". Revista de Pensamiento Crítico.

ALLEMAGNE, Gregory d'

En prensa "Ideología y políticas culturales: representación de la identidad cultural migrante", en L. Suárez Navaz et al. (eds.), Políticas de Representación en Procesos Migratorios. Medios de comunicación y la construcción de la diferencia. Donostia: Mugak.

APPADURAI, Arjun

1996 Modernities at Large: Cultural Dimensions of Globalization. Minneapolis: University of Minnesota Press. 
BAÑón, Antonio

2002 Racismo y diversidad cultural en los medios de comunicación españoles (1995-2000). San Sebastián: Mugak.

BENSON, Rodey R.; NEVEU, Erik

2005 Bourdieu and the Journalistic Field. Cambridge: Polity Press.

BOURDIEU, Pierre

1996 On television. New York: Free Press.

2005 "The Political Field, the Social Field, and the Journalistic Field", en R. Benson y E. Neveu (eds.), Bourdieu and the Journalistic Field. Cambridge: Polity Press, 29-47.

BOYER, Dominic

2006 "Turner's Anthropology of Media and its Legacies". Critique of Anthropology, 26, 1: 47-60.

BOYER, Dominic; HANNERZ, Ulf

2006 "Introduction. Worlds of journalism". Ethnography, 7, 1: 5-17.

CARØE CHRISTIANSEN, C.

2004 "News media consumption among immigrants in Europe. The relevance of diaspora". Ethnicities, 4, 2: 185-207.

CASERO, A.

2004 "Conflicto, noticias e inmigración: construyendo una identidad excluida". Diálogo Comunicación y Diversidad Cultural. Fórum de las Culturas. Barcelona, 21-24 de mayo.

COLLIER, Jane; MAURER, Bill; SUÁREZ NAVAZ, Liliana

1995 "Sanctioned Identities: Legal Constructions of Modern Personhood". Identities. Global Studies in Culture and Power. Special Issue on Law and Identity, 2: 1-2.

CORTEZ, David

2004 "Los discursos de 'ecuatorianidad' en revistas de inmigrantes". Revista Aportes Andinos, diciembre.

DAVILA, Arlene

2001 The Marketing and Making of a People. Berkely: University of California Press.

2008 The Latino Spin: Public Image and the White Whashing of Race. New York: New York University Press.

DYCK, Teum van

2006 "Discurso de las elites y racismo institucional" en M. Lario (coord.), Medios de comunicación e inmigración. Murcia: CAM-Obra Social, 15-34.

2007 “El racismo y la prensa en España", en A. Bañón (ed.), Discurso periodístico y procesos migratorios. Donostia: Gakoa Liburuak, 27-80.

ECHEVARRÍA, Lucía; BRUQUETAS, Sofia

En prensa "Políticas de representación de género en los medios de comunicación de minorías", en L. Suárez Navaz et al. (eds.), Políticas de Representación 
en Procesos Migratorios. Medios de comunicación y la construcción de la diferencia. Donostia: Mugak.

FAVEL, A.; FELDBLUM, M.; SMITH, M. P.

2008 "The human face of global mobility: a research agenda", en The Human Face of Global Mobility: International Highly Skilled Migration in Europe, North America and the Asia-Pacific. New Brunswick: Smith \& Favell, Transaction Publishers.

FAZAL, S. ; TSAGAROUSIANOU, R.

2002 "Diasporic Communication: Transnational Cultural Practices and Communicative Spaces". Javnost-The Public, 9: 5-18.

FERRÁNDEZ FERRER, Alicia

En prensa La construcción del migrante como sujeto político en los medios de comunicación, en L. Suárez Navaz et al. (eds.), Políticas de Representación en Procesos Migratorios. Medios de comunicación y la construcción de la diferencia. Donostia: Mugak.

FITZGERALD, David

2000 Negociating Extra-Territorial Citizenship. Mexican migration and the Transnational Politics of Community. La Jolla: Center for Comparative Immigration Studies.

GAYA, Berta

2003 "Mapping minorities and their media: the nacional context. Spain". European Media Technology and Everyday Network, 2000-2003 (EMTEL). London: School of Economics and Political Science. http://www.lse.ac.uk/collections/EMTEL/ Minorities/papers/spainreport.doc.

GELLNER, Ernest; WATERBURY, J.

1977 Patrons and Clients in Mediterranean Societies. Duckworth: Center for Mediterranean Studies of the American Universities Field Staff.

GEORGIOU, Myria

2006 Diaspora, Identity, and the Media. Diasporic Transnationalism and Mediated Spatialities. Cresskill: Hampton Press.

GILLESPIE, $\mathrm{M}$.

1995 Television, ethnicity and cultural change. London: Routledge.

GÓMEZ-ESCALONILLA, G. (Ed.)

2008 Voces de la inmigración. Medios latinos en Madrid. Madrid: Editorial Universitas.

GUALDA, E.; et al.

2001 IV Congreso sobre la Inmigración en España. Ciudadanía y Participación. Girona, 10-13 de noviembre.

2004 “Textos y fotos de la inmigración en Huelva”. Huelva Información y Odiel Información. 
HARGREAVES, A. G.; MAHDJOUB, D.

1997 "Satellite television viewing among ethnic minorities in France". European Journal of Communication, 12, 4: 459-477.

HUSBAND, C.

1996 "The right to be understood: conceiving the multi-ethnic public sphere". Innovation: The European Journal of Social Sciences, 9, 2: 205-215.

KARIM, K. H.

1998 From ethnic media to global media: transnational communication networks among diasporic communities. http://www.transcomm.ox.ac.uk/working\%20papers/karim. pdf.

LEY, David

2004 "Transnational Spaces and Everyday Lives".Transactions of the Institute of British Geographers, 29, 2: 151-164.

LEY, Melissa

2011 Tranational Middling Migration: Are you rich or are you poor. Manuscrito. Tesis doctoral. Madrid: Universidad Autónoma de Madrid.

LUHMANN, Niklas

2000 The Reality of the Mass Media. Stanford: Stanford University Press.

MACLUHAN, Marshall

1964 Understanding media: The Extensions of Man. New York: McGraw-Hill.

MARCHETTI, Dominique

2005 "Subfields of Specialized Journalism", en R. Benson y E. Neveu (eds.), Bourdieu and the Journalistic Field. Cambridge: Polity Press, 64-82.

MARTÍNEZ CORCUERA, Raúl; AGUIRRE, Anaitze

2010 "Medios 'diaspóricos', Medios generalistas: ¿un instrumento de integración?”, en Minority Media International Conference. An alternative Representation? Ethnic Minority Media, between Hegemony and Resistances. Poitiers, 18-19 March.

PÉREZ, C.

2003 "Los inmigrantes en la prensa: víctimas sin proyecto migratorio". Mugak, 24.

PORTES, Alejandro

2006 "La nueva nación Latina: inmigración y la población Hispana de los Estados Unidos”. REIS, 116/06: 55-96.

RETIS, Jessica

2008 Espacios mediáticos de la inmigración en Madrid: Génesis y evolución. Madrid: Observatorio de las Migraciones y la Convivencia Intercultural de la Ciudad de Madrid. 
RIGONI Isabelle

2003 "Ethnic media, an alternative form of citizenship", en European Conference. London: London School of Economics. 23-26 April.

SANTAMARÍA, Enrique

2002 "Inmigración y barbarie: la construcción social y política del inmigrante como amenaza". Papers: Revista de Sociología, 66: 59-75.

SANTAMARINA, C.

2005 Consumo y ocio de los inmigrantes latinoamericanos en España. Un acercamiento cualitativo. Madrid: Ministerio de Asuntos Sociales.

SCOTT, Sam

2006 "The social morphology of skilled migration: the case of the British middle class in Paris”. Journal of Ethnic and Migration Studies, 32, 7: 1105-1129.

SILVERMAN, Sydel

1977 "Patronage as a Myth", en E. Gellner y J. Waterbury (eds.), Patrons and Clients In Mediterranean Societies. Duckworth: Center for Mediterranean Studies of the American Universities Field Staff, 7-19.

SMITH, Anthony D.

1990 “Towards a Global Culture?”. Theory, Culture \& Society, 7: 171-191.

SOLÉ, Carlota. et al.

2007 El empresariado inmigrante en España. Barcelona: Fundació La Caixa.

SUÁREZ NAVAZ, Liliana

1995a The Concept of habitus, Theorical Influences and Context of the Bourdieuan Work", en Working Papers in Anthropological Enquiries. Stanford: Department of Anthropology.

1995b “La construction d'une communauté transnationale: Les Sénégalais en Andalusie, Espagne”, en Mondes en Développement, 23, 91. Special Issue on Les Dynamiques Migratoires Ouest-Africaines. Dakar: Sylvie Bredeloup ed., ORSTOM.

1999 "Construcción Social del Fetichismo de los Papeles: Ley e Identidad en la Frontera del Sur de Europa”, in Ignasi Terrades (Ed. ) Antropología Jurídica, Santiago de Compostela: FAAEE, 1999.

2004 Rebordering the Mediterranean. Borders and Citizenship in Southern Europe. Oxford: Berghahn Books.

2005 “Ciudadanía y Migración: ¿un oxímoron?”. Puntos de Vista, 4: 29-47.

2007a "A New European Peasant. Immigration and Politics of Space Allocation in Rural Spain”. Peasants, 34, 2, Spring.

$2007 \mathrm{~b}$ "Identitat, territori, i ciutadanies en el camp migratori transnacional". Revista d'Ethnologia de Catalunya, 30, Spring.

2008 "La perspectiva transnacional en los estudios migratorios: génesis, derroteros y surcos metodológicos", en J. García Roca y J. Lacomba (eds.), La inmigración en la sociedad española: una radiografía multidiscriplinar. Barcelona: Bellaterra, 911-40.

2010 "Reflexiones etnográficas sobre la 'ciudadanía transnacional'. Prácticas políticas de andinos en el sur de Europa”. Arbor, 186, 744. 
En prensa Políticas de Representación en Procesos Migratorios. Medios de comunicación y la construcción de la diferencia. Donostia: Mugak.

SUÁREZ NAVAZ, Liliana; FERRÁNDEZ FERRER, Alicia

2011 "Immigrant minority media: Towards a democratisation of the Western mediascape?”, en I. Rigoni y E. Saitta (eds.), Mediating cultural diversity in a globalised public space. Houndmills: Palgrave Macmillan.

SUÁREZ NAVAZ, Liliana; GÓMEZ, Paloma; ARCO, Victor del

En prensa Economía política del espacio mediático migratorio: ¿nuevos medios étnicos?, en L. Suárez Navaz et al. (eds.), Politicas de Representación en Procesos Migratorios. Medios de comunicación y la construcción de la diferencia. Donostia: Mugak.

SUÁREZ NAVAZ, Liliana; HERNÁNDEZ CASTILLO, Aida (Eds.)

2008 Descolonizando el Feminismo. Teorías y practicas desde los márgenes. Madrid: Cátedra.

SUÁREZ NAVAZ, Liliana; MACIÀ, Raquel, y MORENO, Angela (Eds.)

2007 Movimientos de sin-papeles. Hacia una extensión de la ciudadanía. Madrid: Traficantes de Sueños.

TORREGOSA, J. F.

2005 "El tratamiento informativo de la inmigración como paradigma de la alteridad". Pueblos. Revista de Información y Debate, 18: 18-20.

TROUILLOT, M.R.

2001 "The Anthropology of State in the Age of Globalization". Current Anthropology,42, 1: $125-132$.

VERTOVEC, Steven; COHEN, Robin

2005 Conceiving Cosmopolitanism. Theory, Context and Practice. Oxford: Oxford University Press.

VISWANATH, Kasisomayajula; ARORA Pamela

2000 "Ethnic Media in the United States: An Essay on Their Role in Integration, Assimilation, and Social Control". Mass Communication \& Society, 3: 39-56.

WEBER, Max

1978[1922] Selections in translation. Edited by W.G. Grunciman. Cambridge: Cambridge University Press. 